\title{
Health inequalities by education and age in four Nordic countries, 1986 and 1994
}

\author{
K Silventoinen, E Lahelma
}

J Epidemiol Community Health 2002;56:253-258

\begin{abstract}
Study objective: To compare the age pattern of educational health inequalities in four Nordic countries in the mid-1980s and the mid-1990s.

Design: Cross sectional interview surveys at two points of time.

Setting: Data on self reported limiting longstanding illness, and perceived health were collected from Denmark, Finland, Norway, and Sweden in 1986/87 and in 1994/95.

Participants: Representative samples of the non-institutionalised population at 15 years or older. Analyses were restricted to respondents aged between 25 and 75 (n= 23325 men and 24184 women). Response rates varied from $73 \%$ to $87 \%$.

Main results: The age adjusted prevalence of limiting longstanding illness in Finland was 10\% higher in men and $6 \%$ higher in women than in other Nordic countries in 1986/87 but the gap narrowed by 1994/95. Educational health inequalities were largest in Norway. In 1986/87 the odds ratio (OR) for limiting longstanding illness was $11.25(95 \% \mathrm{Cl} 8.66$ to 14.62) among men and $8.23(95 \% \mathrm{Cl} 6.60$ to 10.27 ) among women in the oldest age group (65-74 years old) in Finland when the youngest age group (25-34 years old) was used as the reference category $(O R=1.00)$. The age pattern in Finland was steeper than in Sweden $(\mathrm{OR}=5.02,95 \% \mathrm{Cl} 3.97$ to 6.34 in men and 5.29, 95\% Cl 4.18 to 6.71 in women) or Norway (OR=6.32,95\% Cl 4.06 to 9.84 and $5.45,95 \% \mathrm{Cl} 3.81$ to 7.82 , respectively). In 1994/95 relative health improved in the oldest age group in Finland $(\mathrm{OR}=5.80,95 \% \mathrm{Cl} 4.33$ to 7.78 in men and $5.94,95 \% \mathrm{Cl} 4.52$ to 7.79 in women) and in Norway (OR=4.55, 95\% Cl 3.01 to 6.88 and $3.96,95 \% \mathrm{Cl} 2.70$ to 5.81 , respectively) but remained stable in Sweden. The study compared health differences by age in different educational categories and found that in Finland in $1986 / 87$ the health in the oldest age group was poorer for secondary $(\mathrm{OR}=10.59,95 \% \mathrm{Cl} 5.96$ to $18.82)$ or basic educated $(\mathrm{OR}=9.76,95 \% \mathrm{Cl} 6.66$ to 14.30$)$ men than for men with higher education $(O R=5.15,95 \% \mathrm{Cl} 2.59$ to 10.22$)$. The difference was not found among women or in other Nordic countries and it diminished among men in Finland in 1994/95. The results of perceived health were broadly similar to the above results of limiting longstanding illness.

Conclusion: The results suggest that compared with other Nordic countries the comparatively poorer health in Finland is partly attributable to a cohort effect. This may be associated with the lower standard of living in Finland that lasted until the mid-1950s. The cohort effect is also likely to contribute to educational health inequalities among older Finnish men. The results suggest that not only current social policies but also past economic circumstances are likely to affect the overall health status as well as health inequalities.
\end{abstract}

See end of article for authors' affiliations .....................

Correspondence to: Dr K Silventoinen, Division of Epidemiology, School of Public Health, University of Minnesota, Suite 300, 1300 South Second Street, Minneapolis, MN 55454-1015, USA

karri.silventoinen@helsinki.fi

Accepted for publication 11 September 2001
$\mathrm{S}$ ocioeconomic inequalities in health are well reported all over the world, and in recent years an increasing number of international comparative studies have been made. ${ }^{1}$ Variation in the pattern and magnitude of health inequalities between countries with different social policies, standard of living, and income distribution allows for an examination of the background factors lying behind these inequalities. Moreover, comparatively large health inequalities, on an international basis, in a country suggest that there is a potential for decreasing them. Recent comparisons have, however, questioned previous ideas about direct associations between social structure and health inequalities. Studies concerning both mortality ${ }^{23}$ and morbidity ${ }^{4-6}$ have shown that both relative and absolute health inequalities tend to be wider in the Nordic countries than in Switzerland or southern European countries, for example. This has been regarded as unexpected because the Nordic countries are usually considered as egalitarian societies. ${ }^{7}$

The interpretation of the results of the comparisons is, however, problematic as factors behind the observed health inequalities are likely to vary between countries. Kunst et al ${ }^{8}$ reported that mortality from ischaemic heart disease was strongly related to occupational class in the northern Europe but not in France or the other Mediterranean countries. This is probably attributable to the more healthy Mediterranean diet consumed in these countries. It may emphasise a role for socioeconomic equality in improving healthy lifestyles. Barker $^{9}$ has emphasised the role of fetal life and early childhood in the formation of later inequalities in health. Thus, the variation of the magnitude of health inequalities between countries may be partly attributable to differences in their past economic circumstances. Furthermore, health and welfare policies and the current social structure of society may contribute to socioeconomic inequalities in health. ${ }^{10}$

The aim of this study is to examine the age pattern of health and health inequalities by education from early adulthood to old age in four Nordic countries, Denmark, Finland, Norway, and Sweden. The Nordic countries provide a good basis for comparative research as they have many similarities. For instance, all Nordic countries are welfare states characterised by a relatively high standard of living, effective social policies, and a relatively equal income distribution. ${ }^{11}$ However, before the second world war there were large differences in the standard of living between these countries. In the 1920s and 1930s the Gross Domestic Product in Norway and Finland were respectively about two thirds and one half that of 
Sweden or Denmark. ${ }^{12}$ Their roles in the second world war also varied. Denmark and Norway were occupied by German troops in 1940, whereas Finland fought continually against the Soviet Union in two periods between the years 1939-44. In addition, food rationing continued in Finland until the early 1950s. In contrast, Sweden did not go to war at all. Over the past few decades the gap in the standard of living between the Nordic countries has narrowed and had largely disappeared by the 1980s. ${ }^{7}$

Examining differences in the pattern of health for age cohorts between countries permits the examination of diverse factors affecting health inequalities. Different cohorts have been exposed to different social and economic conditions. We expect, that if past economic circumstances have had an effect on the current health and health inequalities, average health is likely to be poorer and health inequalities larger, particularly among older birth cohorts in Finland compared with the other Nordic countries. Furthermore, such a cohort effect is likely to change over time when more recent healthier birth cohorts replace the older ones. Previous descriptive analyses suggest that health is somewhat poorer in Finland than in the other Nordic countries, especially in older age groups. However, when this gap was measured in 1994, it had narrowed since $1986 .{ }^{13}$ This study extends the analysis to educational inequalities in health across the age structure in four Nordic countries, additionally looking at changes over time from the mid-1980s to the mid-1990s.

\section{METHODS}

The data were obtained from a Nordic data bank ${ }^{14}$ containing harmonised variables collected from comparable cross sectional surveys from Finland (1986 and 1994), Sweden (1986/87 and 1994/95), Norway (1987 and 1995), and Denmark (1987 and 1994). The Finnish, Norwegian, and Swedish "Survey on Living Conditions" were jointly planned and coordinated by the national statistical authorities to be as comparable as possible across countries and over time. The Danish "Health and Morbidity Survey" also contains comparable data on health and other variables included in this study. All datasets were collected using personal interviews, and the samples represent satisfactorily population over $15 / 16$ years in each country. Response rates vary from $73 \%$ to $87 \%$.

Educational attainment (ISCED classification) was used as a measure of socioeconomic status, as it is available for each country and is comparable. Education has been classified in three categories: higher, secondary, and basic education; requiring 13 or more, 10-12, and a maximum of nine years of education respectively. In Finland and Norway information on educational attainment is register based, whereas in Sweden and Denmark education is self reported. There were no major differences in the educational distribution between the countries (table 1). Analyses are restricted to those 25 years or older because younger people may not have finished their education. The oldest people included in the sample vary between countries, therefore analyses were limited to those 75 years or younger.

Self reported limiting longstanding illness is used as a measure of health. It was elicited by a question asking "Do you have any longstanding illness, disability or infirmity?" If the answer was "Yes", a follow up question was asked "Does your illness/disability restrict your work or does it limit your daily activities (gainful employment, housework, schooling, or studying)"?

We classified those reporting limitations to at least some extent as having a limiting longstanding illness. Limiting longstanding illness was not available in the Danish dataset in 1986. Consequently, Denmark was omitted from the analyses of looking at changes over time. We also repeated the analyses by using perceived health below good as an outcome variable to find out whether the results were consistent across the different indicators of health (data not shown). We have no perceived health data from Norway, so Norway was excluded from these analyses. The number of participants in the analyses was 23325 men and 24184 women.

Firstly, descriptive analyses were made (table 1). The prevalence rates for limiting longstanding illness have been standardised using direct age standardisation with cohorts of 10 year. The pooled dataset (men and women from all countries together) was used as the standard population. The index of dissimilarity (ID) was used to measure the magnitude of health inequalities by education. The ID indicates the proportion of cases needed to be redistributed between educational categories to obtain an equal distribution of health. The ID takes into account the different sizes of the categories but does not expect a linear pattern of inequalities. ${ }^{15}$

Statistical models were run by using logistic regression analysis. Results are presented as odds ratios (OR). The purpose of the modelling was to compare relative health differences by age within the three educational groups. Therefore, the youngest age group from each country in 1986/87 and $1994 / 95$ was selected as the reference category $(\mathrm{OR}=1.00)$. The modelling was carried out by examining the age pattern of health (fig 1 and 2). Three interaction terms were fitted to examine systematically the health differences by age (data not shown). Firstly, the interaction between age and year for each country (age.year) was determined. This interaction measures if the age patterns of health were similar between years 1986/87 and 1994/95. Secondly, interaction between country and age (country.age) was computed separately for the years 1986/87 and 1994/95 to determine differences between the countries in the age pattern in health. Thirdly, a second order interaction for country, age, and year (country.age.year) was used to ascertain if the change in the age pattern in health between the two periods had changed between the countries. We expected the age differences to have attenuated more in Finland than in other Nordic countries.

Next, the analyses compared the age pattern of relative health between the three educational categories (table 2). Four interaction terms were fitted (data not shown). These analysed the first order interaction between age and education (age.edu) and second order interaction between age, education, and year (age.edu.year) for each country. These interactions analyse whether there are differences in the age pattern of health between educational categories (age.edu) and whether these differences have changed between the years 1986/87 and 1994/95 (age.edu.year). Second order interactions between age, education, and country (age.edu.country) were used to analyse whether differences between the educational categories in the age pattern of health are similar between countries. We expected the differences to be larger in Finland than in the other countries. Finally, third order interaction between age, education, country, and year (age.edu.country.year) examined whether the magnitude of these differences had changed over time. The modelling was carried out by using the GLIM statistical package. ${ }^{16}$

\section{RESULTS}

Table 1 shows the number of participants and the prevalence of limiting longstanding illness by age and education for each country in 1986/87 and 1994/95. The health differences between men and women were roughly similar between the four countries. Age standardised prevalence of limiting longstanding illness was higher in Finland than in the other Nordic countries. A higher prevalence in Finland was seen in all educational groups. We found a higher prevalence of limiting longstanding illness in Finland especially among older age groups. This prevalence was higher in Finland compared with the other Nordic countries at both periods but the gap between countries narrowed by 1994/95. This narrowing was 


\begin{tabular}{|c|c|c|c|c|c|c|c|c|}
\hline & \multicolumn{2}{|l|}{ Finland } & \multicolumn{2}{|l|}{ Sweden } & \multicolumn{2}{|l|}{ Norway } & \multicolumn{2}{|l|}{ Denmark } \\
\hline & $\%$ & LLI \% & $\%$ & LLI \% & $\%$ & LLI \% & $\%$ & LLI \% \\
\hline \multicolumn{9}{|l|}{ Men 1986/87 } \\
\hline \multicolumn{9}{|l|}{ Age } \\
\hline $25-34$ & 28 & 13 & 24 & 13 & 24 & 11 & 24 & - \\
\hline $35-44$ & 26 & 17 & 25 & 14 & 27 & 16 & 28 & - \\
\hline $45-54$ & 19 & 36 & 18 & 19 & 16 & 26 & 18 & - \\
\hline $55-64$ & 17 & 59 & 17 & 37 & 18 & 37 & 17 & - \\
\hline 65-74 & 10 & 64 & 16 & 44 & 15 & 43 & 13 & - \\
\hline \multicolumn{9}{|l|}{ Education* } \\
\hline Higher & 18 & 19 & 10 & 8 & 22 & 11 & 22 & - \\
\hline Secondary & 33 & 32 & 54 & 20 & 50 & 23 & 53 & - \\
\hline Basic & 49 & 39 & 36 & 28 & 28 & 33 & 25 & - \\
\hline ID by education & 8.8 & & 10.5 & & 11.9 & & - & \\
\hline Total $^{*}$ & $\begin{array}{l}100 \\
(n=4302)\end{array}$ & 34 & $\begin{array}{l}100 \\
(n=4554)\end{array}$ & 23 & $\begin{array}{l}100 \\
(n=1444)\end{array}$ & 24 & $\begin{array}{l}100 \\
(n=1732)\end{array}$ & - \\
\hline \multicolumn{9}{|l|}{ Men 1994/95 } \\
\hline \multicolumn{9}{|l|}{ Age } \\
\hline $25-34$ & 23 & 17 & 23 & 11 & 26 & 17 & 26 & 15 \\
\hline $35-44$ & 27 & 20 & 22 & 13 & 25 & 16 & 25 & 22 \\
\hline $45-54$ & 24 & 29 & 24 & 22 & 24 & 22 & 21 & 26 \\
\hline $55-64$ & 18 & 48 & 16 & 35 & 13 & 36 & 15 & 36 \\
\hline 65-74 & 9 & 54 & 14 & 40 & 12 & 49 & 13 & 38 \\
\hline \multicolumn{9}{|l|}{ Education* } \\
\hline Higher & 24 & 17 & 13 & 9 & 28 & 14 & 27 & 21 \\
\hline Secondary & 39 & 32 & 61 & 21 & 55 & 26 & 53 & 25 \\
\hline Basic & 37 & 35 & 26 & 31 & 17 & 39 & 20 & 34 \\
\hline ID by education & 10.2 & & 10.6 & & 12.2 & & 6.4 & \\
\hline Total $^{*}$ & $\begin{array}{l}100 \\
(n=3628)\end{array}$ & 31 & $\begin{array}{l}100 \\
(n=4549)\end{array}$ & 22 & $\begin{array}{l}100 \\
(n=1396)\end{array}$ & 26 & $\begin{array}{l}100 \\
(n=1720)\end{array}$ & 26 \\
\hline \multicolumn{9}{|l|}{ Women 1986/87 } \\
\hline \multicolumn{9}{|l|}{ Age } \\
\hline $25-34$ & 25 & 16 & 22 & 13 & 25 & 18 & 25 & - \\
\hline $35-44$ & 25 & 23 & 26 & 17 & 25 & 20 & 26 & - \\
\hline $45-54$ & 18 & 39 & 18 & 23 & 15 & 32 & 18 & - \\
\hline $55-64$ & 18 & 56 & 17 & 41 & 18 & 34 & 17 & - \\
\hline 65-74 & 14 & 61 & 17 & 44 & 17 & 55 & 14 & - \\
\hline \multicolumn{9}{|l|}{ Education* } \\
\hline Higher & 14 & 25 & 9 & 16 & 15 & 19 & 18 & - \\
\hline Secondary & 34 & 32 & 52 & 24 & 49 & 29 & 43 & - \\
\hline Basic & 52 & 38 & 39 & 29 & 36 & 32 & 39 & - \\
\hline ID by education & 5.9 & & 5.8 & & 5.0 & & - & \\
\hline Total $^{*}$ & $\begin{array}{l}100 \\
(n=4846)\end{array}$ & 35 & $\begin{array}{l}100 \\
(n=4526)\end{array}$ & 25 & $\begin{array}{l}100 \\
(n=1542)\end{array}$ & 29 & $\begin{array}{l}100 \\
(n=1770)\end{array}$ & - \\
\hline \multicolumn{9}{|l|}{ Women 1994/95 } \\
\hline \multicolumn{9}{|l|}{ Age } \\
\hline $25-34$ & 23 & 20 & 22 & 14 & 27 & 22 & 24 & 16 \\
\hline $35-44$ & 27 & 24 & 22 & 16 & 25 & 25 & 24 & 25 \\
\hline $45-54$ & 23 & 33 & 24 & 23 & 21 & 33 & 22 & 28 \\
\hline $55-64$ & 16 & 50 & 17 & 35 & 14 & 44 & 16 & 47 \\
\hline 65-74 & 11 & 59 & 15 & 44 & 13 & 53 & 14 & 53 \\
\hline \multicolumn{9}{|l|}{ Education* } \\
\hline Higher & 19 & 25 & 12 & 26 & 24 & 23 & 27 & 23 \\
\hline Secondary & 44 & 34 & 61 & 34 & 53 & 34 & 46 & 28 \\
\hline Basic & 37 & 39 & 27 & 40 & 23 & 39 & 27 & 41 \\
\hline ID by education & 5.3 & & 4.2 & & 2.9 & & 9.7 & \\
\hline Total * & $\begin{array}{l}100 \\
(n=3574)\end{array}$ & 33 & $\begin{array}{l}100 \\
(n=4650)\end{array}$ & 24 & $\begin{array}{l}100 \\
(n=1414)\end{array}$ & 33 & $\begin{array}{l}100 \\
(n=1862)\end{array}$ & 31 \\
\hline
\end{tabular}

*The prevalence of $\mathrm{LI}$ have been adjusted for age.

especially due to the decreasing prevalence among 45-54 year old men and women. The prevalence among Finns 55 years or older remained relatively high for both time periods.

Educational health inequalities were largest among Norwegian men as measured by the ID (11.9 in 1986/87 and 12.2 in 1994/95). The smallest inequalities among men were found in Denmark in 1994/1995 (ID=6.4). This was attributable to a higher prevalence of limiting longstanding illness among Danish men with high education compared with the other Nordic countries. Health inequalities among women were smaller overall than among men. This was mainly attributable to the relatively high prevalence in women of higher education. The largest inequalities were found in Norway similarly with men.

Figure 1 shows the results of the logistic regression analyses by age for men. In 1986/87 the odds ratio of limiting longstanding illness among the oldest cohort of Finnish men (65-74 years old) was 11.25 (95\% CI 8.66 to 14.62) when the youngest age group (25-34 years old) was used as the reference category $(\mathrm{OR}=1.00)$. This age difference was larger 


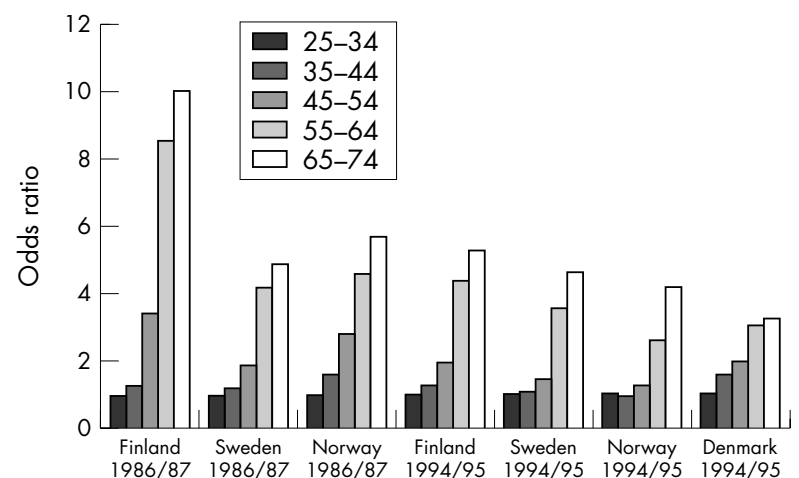

Figure 1 Logistic regression analysis for limiting longstanding illness by age, year, and country among men.

than that found in Sweden (OR=5.02, 95\% CI 3.97 to 6.34) or in Norway ( $\mathrm{OR}=6.32,95 \%$ CI 4.06 to 9.84$)$. The health differences between the countries by age were statistically significant $(p=0.001$ for country.age interaction). In 1994/95 the relative health improved among oldest Finnish men and the odds ratio was 5.80 (95\% CI 4.33 to 7.78$)$. A similar improvement was also found among oldest Norwegian men $(\mathrm{OR}=4.55,95 \%$ CI 3.01 to 6.88$)$ but among the Swedish men the relative health differences remained roughly at a similar level as in $1986 / 67$ (OR=5.41, 95\% CI 4.20 to 6.98). This nar-

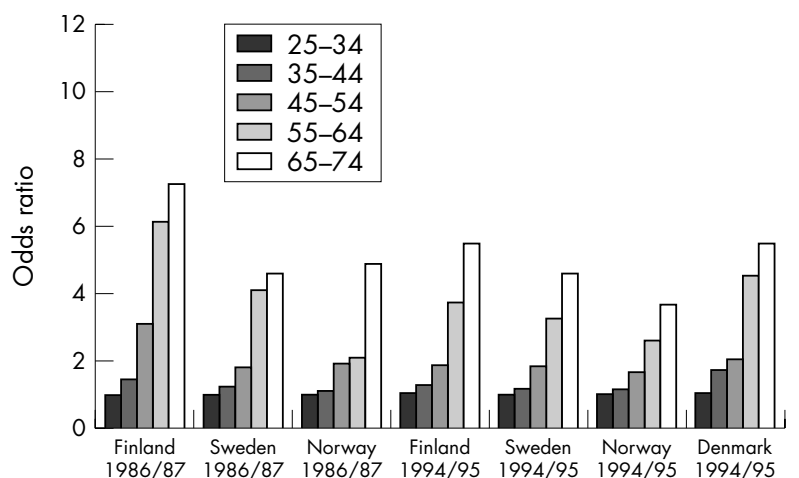

Figure 2 Logistic regression analysis for limiting longstanding illness by age, year, and country among women.

rowing was statistically significant in Finland $(p=0.001$ for age.year interaction) and borderline significant in Norway $(p=0.077)$. Despite the narrowing age differences these differences between countries were still statistically significant in 1994/95 ( $\mathrm{p}=0.015$ for country.age interaction). The change of relative health from 1986/87 to 1994/95 was different between the countries as indicated by the interaction between country, age, and year $(\mathrm{p}=0.001)$.

Figure 2 presents the corresponding analyses for women. The oldest Finnish women had poorer relative health

Table 2 Logistic regression analysis for limiting longstanding illness by age, year, education, and country among men and women

\begin{tabular}{|c|c|c|c|c|c|c|c|}
\hline & \multicolumn{2}{|l|}{ Finland } & \multicolumn{2}{|l|}{ Sweden } & \multicolumn{2}{|l|}{ Norway } & \multirow{2}{*}{$\frac{\text { Denmark }}{1994 / 95 \text { OR }}$} \\
\hline & 1986/87 OR & $1994 / 95$ OR & 1986/87 OR & 1994/95 OR & 1986/87 OR & $1994 / 95$ OR & \\
\hline \multicolumn{8}{|l|}{ Men } \\
\hline \multicolumn{8}{|c|}{ Higher education } \\
\hline $25-34$ & 1.00 & 1.00 & 1.00 & 1.00 & 1.00 & 1.00 & 1.00 \\
\hline $35-44$ & 0.39 & 2.42 & 1.04 & 1.91 & 2.26 & 1.33 & 1.90 \\
\hline $45-54$ & 1.46 & 2.07 & 0.89 & 3.47 & 4.73 & 2.42 & 2.04 \\
\hline $55-64$ & 4.00 & 7.19 & 2.68 & 4.98 & 6.55 & 1.76 & 3.99 \\
\hline $65-74$ & 5.15 & 9.38 & 2.93 & 4.79 & 9.45 & 5.09 & 7.08 \\
\hline \multicolumn{8}{|c|}{ Secondary education } \\
\hline $25-34$ & 1.00 & 1.00 & 1.00 & 1.00 & 1.00 & 1.00 & 1.00 \\
\hline $35-44$ & 1.72 & 1.30 & 1.08 & 1.03 & 1.28 & 0.94 & 1.49 \\
\hline $45-54$ & 3.95 & 2.27 & 1.48 & 2.14 & 2.42 & 1.20 & 2.21 \\
\hline $55-64$ & 9.48 & 4.78 & 3.79 & 3.50 & 3.14 & 2.39 & 2.57 \\
\hline $65-74$ & 10.59 & 8.04 & 4.56 & 4.13 & 3.79 & 3.62 & 3.35 \\
\hline \multicolumn{8}{|c|}{ Basic education } \\
\hline $25-34$ & 1.00 & 1.00 & 1.00 & 1.00 & 1.00 & 1.00 & 1.00 \\
\hline $35-44$ & 1.30 & 0.90 & 0.94 & 1.46 & 2.73 & 1.00 & 1.38 \\
\hline $45-54$ & 3.34 & 1.69 & 1.36 & 1.81 & 2.81 & 1.01 & 1.23 \\
\hline $55-64$ & 7.97 & 3.27 & 2.71 & 3.59 & 7.31 & 3.06 & 2.34 \\
\hline $65-74$ & 9.76 & 3.61 & 3.50 & 4.13 & 6.47 & 4.38 & 1.48 \\
\hline \multicolumn{8}{|c|}{ Women } \\
\hline \multicolumn{8}{|c|}{ Higher education } \\
\hline $25-34$ & 1.00 & 1.00 & 1.00 & 1.00 & 1.00 & 1.00 & 1.00 \\
\hline $35-44$ & 1.01 & 1.57 & 1.24 & 1.14 & 1.14 & 0.97 & 2.08 \\
\hline $45-54$ & 1.78 & 1.53 & 1.46 & 1.48 & 0.74 & 1.41 & 2.29 \\
\hline $55-64$ & 5.54 & 3.18 & 6.13 & 2.53 & 2.47 & 1.25 & 4.54 \\
\hline $65-74$ & 8.58 & 7.11 & 3.70 & 4.85 & 9.33 & 1.81 & 4.13 \\
\hline \multicolumn{8}{|c|}{ Secondary education } \\
\hline $25-34$ & 1.00 & 1.00 & 1.00 & 1.00 & 1.00 & 1.00 & 1.00 \\
\hline $35-44$ & 1.70 & 1.11 & 1.39 & 1.32 & 1.15 & 1.17 & 1.42 \\
\hline $45-54$ & 3.15 & 1.80 & 1.73 & 2.38 & 2.28 & 1.62 & 1.38 \\
\hline $55-64$ & 4.84 & 3.69 & 4.42 & 3.48 & 2.10 & 2.17 & 3.16 \\
\hline $65-74$ & 6.71 & 5.06 & 5.35 & 4.72 & 3.47 & 3.51 & 4.93 \\
\hline \multicolumn{8}{|c|}{ Basic education } \\
\hline $25-34$ & 1.00 & 1.00 & 1.00 & 1.00 & 1.00 & 1.00 & 1.00 \\
\hline $35-44$ & 1.40 & 1.55 & 1.12 & 0.68 & 0.88 & 1.78 & 2.01 \\
\hline $45-54$ & 3.11 & 2.21 & 1.80 & 0.85 & 1.47 & 2.47 & 2.62 \\
\hline $55-64$ & 5.92 & 3.89 & 3.20 & 1.61 & 1.76 & 4.81 & 3.99 \\
\hline $65-74$ & 6.60 & 5.13 & 3.61 & 1.94 & 4.54 & 4.83 & 4.49 \\
\hline
\end{tabular}




\section{Key points}

- Currently, the Nordic countries share similar social and health policies, but in the past, economic conditions were different as Finland used to be the poorest Nordic country.

- We compared the pattern of health inequalities for age and for education between four Nordic countries to examine whether different factors contribute to the level of health and educational health inequalities.

- In older age groups health was poorer and educational inequalities among men larger in Finland compared to the other Nordic countries than in younger age groups in the mid-1980s, but these gaps largely disappeared by the mid1990s.

- Poorer health in Finland is likely to be a cohort effect resulting from poorer past economic conditions prior to the 1950s.

- Not only current social policies but also past economic circumstances contribute to the level of health as well as the magnitude of socioeconomic inequalities in health.

$(\mathrm{OR}=8.23,95 \% \mathrm{CI} 6.60$ to 10.27$)$ than the same cohort in Sweden $(\mathrm{OR}=5.29,95 \%$ CI 4.18 to 6.71$)$ and Norway $(\mathrm{OR}=5.45,95 \% \mathrm{CI} 3.81$ to 7.82$)$. These differences between the countries were statistically significant $(p=0.001$ for country.age interaction). In 1994/95 the relative health improved among oldest Finnish (OR=5.94, 95\% CI 4.52 to 7.79 ) and Norwegian women $(\mathrm{OR}=3.96,95 \% \mathrm{CI} 2.70$ to 5.81$)$ but remained stable among old Swedish women (OR=5.01, 95\% CI 3.96 to 6.34 ). The narrowing was statistically significant in Finland ( $p=0.002$ for country.age interaction).

Table 2 presents the logistic regression analyses by age and education for men and women. The increase in the prevalence of limiting longstanding illness by age in Finland was steeper among men with secondary or basic education than among higher educated men in 1986/87. This is seen as a lower odds ratio in the oldest age group in higher educated men $(\mathrm{OR}=5.15,95 \% 2.59$ to 10.22$)$ compared with secondary $(\mathrm{OR}=10.59,95 \%$ CI 5.96 to 18.82$)$ or basic educated $(\mathrm{OR}=9.76,95 \%$ CI 6.66 to 14.30$)$ men. The differences in the age pattern between educational categories were statistically significant $(\mathrm{p}=0.032$ for age.edu interaction). No difference in the educational age pattern for health was seen among Finnish men in 1994/95. This narrowing inequality among men in Finland by age was statistically significant $(p=0.01)$ as indicated by the interaction between age, education, and year. There were no differences in the age pattern between the educational groups among women in any Nordic country.

The analyses were repeated by using perceived health as below good as a health outcome excluding Norway as the data were not available. The results were very similar with the results of limiting longstanding illness (data not shown). In 1986/87 the odds ratios of perceived health was 15.87 (95\% CI 12.1 to 20.9) among the oldest cohort of Finnish men and 15.68 (95\% CI 12.4 to 19.9) among the oldest Finnish women. This is higher than that found in Sweden (OR=6.58, 95\% CI 5.13 to 8.44 in men and $5.54,95 \%$ CI 4.36 to 7.04 in women) or in Denmark (OR $=7.94,95 \%$ CI 5.07 to 12.44 and $8.02,95 \%$ CI 5.36 to 12.01, respectively). The differences between countries were statistically significant ( $p$ value $=0.001$ for country. age interaction in men and women). In 1994/95 the relative health among the oldest men improved in Finland $(\mathrm{OR}=8.51$, $95 \%$ CI 6.32 to 11.47 in men and $11.37,95 \%$ CI 8.51 to 15.19 in women) and Denmark (OR=5.65, 95\% CI 3.55 to 9.00 and $5.15,95 \%$ CI 3.53 to 7.50 , respectively) but remained stable in Sweden $(6.13,95 \%$ CI 4.72 to 7.98 and $5.10,95 \%$ CI 4.05 to 6.44 , respectively). The health differences by age were still statistically significant between the countries in 1994/95 ( $p=0.02$ for country.age interaction in men and 0.001 in women).

The age pattern of perceived health by education was similar with that for limiting longstanding illness - that is, steeper

\section{Policy implications}

- Our results suggest that poor childhood living conditions damage health and cause wide socioeconomic health differences decades later. Therefore, it is important to protect children against the effects of poor conditions, such as inadequate nutrition and starting physically hard work too early. Safeguarding adequate childhood living conditions is likely to have longlasting beneficial effects on health in society.

- In rapidly developing countries, the burden of past economic conditions needs to be taken into account in the current public health policies. Older birth cohorts may need more health care than younger cohorts when they reach the same age. The retirement age may also need to be lower in the older cohorts, especially among those who have a very long work career in physically exhausting occupations.

- In comparisons between countries the current level of health is likely to be a poor indicator of the efficiency of public health policies. In countries that have suffered from past poverty the costs of health care tend to be higher and the level of health poorer than in countries with a more affluent economic history. Thus, the results of international comparisons need to be interpreted with caution, taking into account not only the current situation but also past conditions.

among basic or secondary educated Finnish men compared with men with higher education in 1986/87. The odds ratio among the oldest men with higher education was 9.56 (95\% CI 4.88 to 18.7 ) whereas it was 11.28 (95\% CI 6.24 to 20.42 ) among secondary and 15.94 (95\% CI 10.70 to 23.90) among basic educated men of the oldest cohort. The differences in the age pattern between educational categories were statistically significant $(p=0.004$ for age.edu interaction). These differences were not observed in 1994/95 among Finnish men. We did not find any differences among Finnish women or among men or women in the other countries.

\section{DISCUSSION}

Our results show that among the four studied Nordic countries, health was poorest in Finland. However, this is not because of large socioeconomic health inequalities in Finland in itself, but rather to the age pattern of health. When comparing differences in limiting longstanding illness and perceived health by age cohort with the other Nordic countries we found that the relative health was poorer in the older age groups in Finland. Health among older Finns was especially poor in 1986/87, but this pattern was less obvious by 1994/95. Compared with the other Nordic countries, the health in the old age groups was still poorer in Finland among men and women. A similar narrowing of health differences by age was also found in Norway and Denmark but their health differences in 1986/87 were already smaller than those among Finnish men. The datasets in Norway and Denmark were also smaller than in Finland and thus these results might not reach statistical significance.

Relative health by age between educational categories showed that Finnish men's health inequalities differed from that of men in the other Nordic countries. Educational health inequalities for limiting longstanding illness and perceived health in older age groups compared with those in younger age groups were larger in Finland than in the other Nordic countries in 1986/87. This difference had largely disappeared by 1994/95. Previous studies ${ }^{17-20}$ have suggested that the socioeconomic inequalities in health are narrower in older ages compared with the middle aged. This is probably because of the weakening effect of working conditions and an increasing proportion of retired people in older cohorts. Thus, in Finland there may be other factors that exacerbate educational health 
inequalities in older age groups. However, these factors do not make overall health inequalities in Finland larger than in the other Nordic countries, because we found the largest health inequalities among Norwegian men. Health inequalities among men were smallest in Denmark. This was not attributable to good health among Danish men with basic education, but instead to comparatively poor health among men with higher education. For the same reason health inequalities were smaller among women than among men. These findings suggest that different factors contribute to the magnitude of educational health inequalities between the Nordic countries.

The comparatively poor health in the older age groups and the decline of this pattern over time suggest that poor health in Finland is at least partly attributable to a cohort effect. The turning point in Finland seems to be the cohorts born between 1941-1951. In the 1986/87 data the health in this cohort (45-54 years) and older cohorts was clearly poorer than for comparable cohorts in the other Nordic countries. In 1994/95 a similar difference could be found but the turning point in Finland was now between those aged 55-64 and older-that is, the same birth cohort as that found in 1986/87. Thus, the health difference is not likely to be attributable to an age effect in itself but rather to a cohort effect. This cohort effect can be understood when seen against the poor standard of living in Finland that prevailed until the early 1950s.

One possible factor for the cohort effect is nutritional deprivation. This is supported by our previous study that found that average stature was shorter in Finland than in Sweden in the cohorts born before the second world war. However, this gap narrowed in cohorts born after the second world war. ${ }^{21}$ The short stature of older Finns could be indicative of nutritional deprivation in childhood. The results from Norway, which were similar but less dramatic than in Finland, are also in accordance with this conclusion. Before the second world war Norway was a poorer country than Sweden but the gap between these countries was not as large as that between Finland and Sweden.

Our results suggest that not only current but also past economic circumstances influence the overall level of health and the magnitude of relative socioeconomic inequalities in health. Currently, the Nordic countries have moved closer to each other in economic terms, ${ }^{7}$ but the effects of the poorer past economic conditions on health are still visible. Therefore, it may not be realistic to expect that even major improvements in the standard of living would have immediate effects on the health status and health inequalities in a population in general and among elderly people in particular. Thus, it is not reasonable to expect that in rapidly developing economies health would improve simultaneously with the standard of living or, the other way round, to expect that an economic downturn would not have an effect on health if no decline in health could be found after a few years follow up. Furthermore, it is not possible to fully credit the magnitude of health inequalities in society to the current social structure, economic circumstances, and health and welfare policies. Nevertheless, the deep roots of health inequalities also emphasise the importance of current health and welfare policies, as these, too, are likely to have long term effects on health and health inequalities that may be difficult to fully compensate by future health and welfare policies.

\section{ACKNOWLEDGEMENTS}

This paper has been prepared within a "A comparative project on social determinants of health in the Nordic countries", coordinated at the Department of Public Health, University of Helsinki, Finland. We are grateful to the Nordic team members who have contributed to the design of the project and provided national data (see www.kttl.helsinki.fi/projektit/helsinki/nordiccomparisons).

Funding: the study has been supported by grants from the Joint Nordic Committee of the Nordic Social Science Research Councils (NOS-S) and the Academy of Finland (no 37800 and no 48553).

Conflicts of interest: none.

\section{Authors' affiliations}

K Silventoinen, E Lahelma, Department of Public Health, University of Helsinki, Finland

\section{REFERENCES}

1 Mackenbach JP, Kunst AE, Cavelaars AEJM, et al. Socioeconomic inequalities in morbidity and mortality in western Europe. Lancet 1997;349: 1655-9.

2 Kunst AE, Mackenbach JP. The size of mortality differences associated with educational level in nine industrialized countries. Am J Public Health 1994;84:932-7.

3 Kunst AE, Groenhof F, Mackenbach JP. Mortality by occupational class among men 30-64 years in 11 European countries. Soc Sci Med 1998:46: 1459-76.

4 Cavelaars AEJM, Kunst AE, Geurts JJM, et al. Morbidity differences by occupational class among men in seven European countries: an application of the Erikson-Goldthorpe social class scheme. Int J Epidemiol 1998;27:222-30.

5 Cavelaars AEJM, Kunst AE, Geurts JJM, et al. Differences in self reported morbidity by educational level: a comparison of 11 Western European countries. J Epidemiol Community Health 1998;52:219-27.

6 Kunst AE, Geurts JJM, Berg J. International variation in socioeconomic inequalities in self reported health. J Epidemiol Community Health 1995;49:117-23.

7 Kautto M, Fritzell J, Hvinden B, et al, eds. Nordic welfare states in the European context. London: Routledge; 2001

8 Kunst AE, Groenhof F, Andersen O, et al. Occupational class and ischemic heart disease mortality in the United States and 11 European countries. Am J Public Health 1999;89:47-53.

9 Barker DJP. Mothers, babies and health in later life. 2nd edn. Edinburgh: Churchill Livingstone, 1998.

10 Maclntyre S. A review of the social patterning and significance of measures of height, weight, blood pressure and respiratory function. Soc Sci Med 1988;27:327-37.

11 Fritzell J. Still different? Income distribution in the Nordic countries in a European comparison. In: Kautto M, Fritzell J, Hvinden B, et al, eds. Nordic welfare states in the European context. London: Routledge, 2001:18-41.

12 Alestalo $\mathbf{M}$, Kuhnle S. The Scandinavian route: economic, social and political developments in Denmark, Finland, and Sweden. In: Hansen E, Ringen S, eds. The Scandinavian model. London: ME Sharpe, Ringen S, eds.

13 Roos E, Kivelä K, Lahelma E, et al. Har ojämlikheten i hälsa ökat eller minskat i Norden på 1980- och 1990-talet? [(Have inequalities in health increased or decreased in Nordic countries in the 1980s and the 1990s?]. Läkartidningen 2001;98: 2576-84.

14 Lahelma E, Kivelä K, Roos E, et al. Analysing changes of health inequalities in the Nordic welfare states. Soc Sci Med (in press).

15 Mackenbach JP, Kunst AE. Measuring the magnitude of socio-economic inequalities in health: an overview of available measures illustrated with two examples from Europe. Soc Sci Med 1997;44:757-71.

16 Aitkin M, Anderson D. Statistical modelling in GLIM. Oxford: Oxford Statistical Science Series, 1990.

17 House JS, Kessler RC, Herzog AR, et al. Age, socioeconomic status, and health. Milbank Q 1990;68:383-411.

18 House JS, Lepkowski JM, Kinney AM, et al. The social stratification of aging and health. Health Soc Behav 1994;35:213-34.

19 Ford G, Ecob R, Hunt K, et al. Patterns of class inequality in health through the lifespan: class gradients at 15,35 and 55 years in the West of Scotland. Soc Sci Med 1994;39:1037-50.

20 Arber S, Cooper H. Gender and inequalities in health across the lifecourse. In: Annandale E, Hunt K, eds. Gender inequalities in health. Buckingham: Open University Press, 2000: 123-49.

21 Silventoinen K, Lahelma E, Lundberg O, et al. Body-height, birth cohort and social background in Finland and Sweden. Eur J Public Health 2001;11:124-9. 